\title{
Magnetic Resonance Imaging of the Hippocampal Formation and Mammillary Nuclei Distinguish Medial Temporal Lobe and Diencephalic Amnesia
}

\author{
L. R. Squire, ${ }^{1}$ D. G. Amaral, ${ }^{2}$ and G. A. Press ${ }^{3}$ \\ 'Department of Veterans Affairs Medical Center, San Diego, California 92161 and Department of Psychiatry, University of \\ California at San Diego, La Jolla, California 92093, ${ }^{2}$ The Salk Institute, San Diego, California 92138, and ${ }^{3}$ Department of \\ Radiology and Magnetic Resonance Institute, University of California, School of Medicine, San Diego, California 92103
}

\begin{abstract}
Studies of circumscribed amnesia have been a useful source of information about the organization of human memory functions. In an effort to obtain neuroanatomical information about the patients being studied, we have used 2 high-resolution protocols for imaging the human brain with magnetic resonance (MR). One provides images of the hippocampus, permitting visualization of the hippocampal formation in considerable detail. The second provides images of the mammillary nuclei. Four amnesic patients with alcoholic Korsakoff's syndrome had abnormally small mammillary nuclei that were barely detectable by MR in most cases. The temporal lobe, hippocampal formation, and parahippocampal gyrus were of normal size. In a second group of $\mathbf{4}$ (non-Korsakoff) amnesic patients, the opposite findings were obtained. The hippocampal formation was markedly reduced in size in the absence of a detectable change in the size of the temporal lobe. By contrast, the mammillary nuclei, though somewhat reduced in volume, were considerably larger than in the patients with Korsakoff's syndrome. The anatomical findings for individual patients generally corresponded to the severity of their memory impairment. The results show that neuroimaging techniques can distinguish between patients with diencephalic and medial temporal lobe amnesia. These techniques can therefore provide useful information about the crucial issue of patient classification, and they set the stage for exploring possible quantitative and qualitative differences between patients.
\end{abstract}

During the past several decades, cognitive studies of memory impairment have provided valuable information about the structure and organization of memory functions (Rapaport, 1942; Talland, 1965; Milner, 1972; Butters and Cermak, 1980; Baddeley, 1982; Schacter, 1985; Squire, 1986; Weiskrantz, 1987). In contrast, only limited neuropathological information has been available about the patients being studied. Postmortem studies of patients known to have been amnesic during life have shown

Received Feb. 16, 1990; revised Apr. 17, 1990; accepted May 8, 1990

We thank J. Zouzounis, K. Fuchs, M. Arzaga, and K. Trulock for assistance. This work was supported by the Mcdical Rescarch Service of the Department of Veterans Affairs, NIMH Grants MN24600 and MH41479, NIH Grant NS16980, the McKnight Foundation, the Office of Naval Research, and a Bioscience Grant for International Joint Research from the NEDO, Japan.

Correspondence should be addressed to Larry R. Squire, Veterans Administration Medical Center, 3350 La Jolla Village Drive, San Diego, CA 92161.

Copyright C 1990 Society for Neuroscience $0270-6474 / 90 / 093106-12 \$ 03.00 / 0$ that damage to the medial temporal lobe or midline diencephalic regions results in memory impairment (for reviews. see Brierley. 1977; Damasio, 1984; Squire, 1987; Markowitsch, 1988; Victor et al., 1989). Unfortunately, quantitative neurobehavioral data and detailed neuropathological information have rarely been available in the same patients. In 1 case, memory impairment was associated with bilateral damage restricted to the CAl region of the hippocampus (Zola-Morgan et al., 1986). In 4 patients with Korsakoff's syndrome, memory impairment was associated with damage in the mammillary nuclei and medial thalamus (Mair et al., 1979; Mayes et al., 1988). More recently. brain structures and connections involved in memory functions have been identified using an animal model of human amnesia in the monkey (Mishkin et al., 1982; Squire and Zola-Morgan, 1983; Mahut and Moss, 1984; Zola-Morgan and Squire, 1990; Zola-Morgan et al., 1990).

Using modern neuroimaging techniques, it has now become possible to relate memory impairment to neuropathology in living patients. Imaging techniques were first applied to amnesic patients who had medial thalamic lesions (Squire and Moore. 1979; Winocur et al., 1984; Graff-Radford et al., 1985; Mori et al., 1986; von Cramon et al., 1985; Squire et al., 1989a) or postencephalitic temporal lobe lesions (Damasio et al., 1985). In order to obtain more detailed information about the locus of damage in amnesic patients, we have developed a high-resolution protocol for imaging the human hippocampus with magnetic resonance (MR). This protocol permits visualization of the hippocampal formation in considerable detail (Press et al., 1989). With this protocol, abnormalities in the HF were demonstrated in 3 patients with circumscribed amnesia.

Because of the importance of distinguishing medial temporal lobe pathology and diencephalic pathology in amnesic patients. we have extended the imaging protocol for the hippocampus to patients with alcoholic Korsakoff's syndrome, the best-studied cxample of dicncephalic amnesia. We also developed a second protocol (modified from Charness and De LaPaz, 1987) to image the mammillary nuclei, because these structures are reportedly damaged in all patients with Wernicke-Korsakoff's syndrome (Victor et al., 1989). The present study applied both imaging protocols (hippocampus and mammillary nuclei) to 3 subject groups: 4 patients with alcoholic Korsakoff's syndrome, 4 nonKorsakoff amnesic patients, and 6 normal subjects. In this way, we explored the possibility of using neuroimaging techniques to classify amnesic patients on the basis of anatomical criteria. 
Table 1. Subject characteristics

\begin{tabular}{|c|c|c|c|c|c|c|c|}
\hline \multirow[b]{2}{*}{ Group } & \multirow[b]{2}{*}{ Age } & \multirow[b]{2}{*}{ WAIS-R } & \multicolumn{5}{|l|}{ WMS-R } \\
\hline & & & $\begin{array}{l}\text { Attention/ } \\
\text { conccn- } \\
\text { tration }\end{array}$ & Verbal & Visual & General & Delay \\
\hline \multicolumn{8}{|l|}{ Korsakoffs } \\
\hline $\mathrm{RC}$ & 73 & 106 & 115 & 76 & 97 & 80 & 72 \\
\hline DM & 55 & 101 & 92 & 55 & 64 & 50 & 51 \\
\hline PN & 62 & 94 & 81 & 77 & 73 & 67 & 53 \\
\hline JW & 53 & 98 & 104 & 65 & 70 & 57 & 57 \\
\hline Mean & 60.8 & 99.8 & 98.0 & 68.3 & 76.0 & 63.5 & 58.3 \\
\hline \multicolumn{8}{|c|}{ Non-Korsakoffs } \\
\hline WH & 66 & 113 & 88 & 72 & 82 & 67 & $<50$ \\
\hline WI & 75 & 104 & 92 & 72 & 82 & 71 & 58 \\
\hline $\mathrm{JL}$ & 69 & 116 & 122 & 73 & 83 & 74 & 58 \\
\hline LM & 58 & 111 & 132 & 87 & 96 & 90 & 65 \\
\hline Mean & 67.0 & 111.0 & 108.5 & 76.0 & 85.8 & 75.5 & 57.8 \\
\hline \multicolumn{8}{|l|}{ Controls } \\
\hline MB & 74 & 123 & 126 & 93 & 106 & 96 & 102 \\
\hline $\mathrm{RC}$ & 65 & 103 & 92 & 96 & 109 & 102 & 102 \\
\hline WG & 70 & 110 & 111 & 91 & 93 & 89 & 100 \\
\hline $\mathbf{J H}$ & 70 & 117 & 95 & 104 & 120 & 111 & 115 \\
\hline NH & 57 & 119 & 114 & 114 & 120 & 121 & 138 \\
\hline $\mathrm{JM}$ & 63 & 137 & 124 & 125 & 123 & 129 & 138 \\
\hline Mean & 66.5 & 118.2 & 110.3 & 103.8 & 111.8 & 108.0 & 115.8 \\
\hline
\end{tabular}

WAIS-R, Wechsler Adult Intelligence Scale-Revised; WMS-R, Wechsler Memory Scale-Revised. The WAIS-R and each of the 5 indices of the WMS-R yield a mean score of 100 in the normal population with a standard deviation of 15. The WMS-R does not provide numerical scores for subjects who score below 50 . Therefore, the value below 50 was scored as 50 for computing a group mean.

\section{Materials and Methods}

\section{Subjects}

Patients with Korsakoff's syndrome. Three men and 1 woman with alcoholic Korsakoff's syndrome were examined (RC, DM, PN, and JW). All 4 patients have been studied in our laboratory for several years, and their memory impairment is well documented (Janowsky et al., 1989; also see patients K4-K7 in Squire et al., 1989b). Three of the 4 patients (DM, PN, and JW) participated in an earlier quantitative computed tomography (CT) study (Shimamura et al., 1988)

These 4 patients averaged 60.8 years of age at the time of the MR examination. They had an average of 11.5 years of education and a mean Wechsler Adult Intelligence Scale-Revised (WAIS-R) IQ of 99.8. Individual IQ scores and Wechsler Memory Scale-Revised (WMS-R) index scores are shown in Table 1 (Wechsler, 1987; Butters et al., 1988) Immediate and delayed $(12 \mathrm{~min})$ recall of a short prose passage averaged 5.0 and 0 segments, respectively (21 segments total). Scores on other memory and cognitive tests are shown in Tables 2 and 3. Note that the scores on the word-recall test in Table 2 are above 0 because, on this test of immediate recall, several items can be retrieved from immediate memory, which is intact in amnesia. Additional neuropsychological data for these 4 patients and scores for matched control subjects can be found elsewhere (Janowsky et al., 1989).

Other patients with amnesia. Four additional men with circumscribed amnesia were examined (WH, WI, JL, and LM). Two of these patients (WH and LM) have been tested in the laboratory for several years, and their memory impairment is well documented (Janowsky et al., 1989; Squire et al., 1989). All 4 patients have participated in previous neuropsychological studies of memory (Squire and Frambach, 1990), and 3 of the patients (WH, JL, and LM) participated in an earlier MR study (Press et al., 1989). WH became amnesic rapidly during the course of several days in 1986 without antecedent head trauma, seizure, or unconsciousness. WI and JL both became amnesic gradually during a period of about 2 years (for WI, 1983-1985; for JL, 1985-1987); their cognitive status has remained stable since that time. The etiology of the amnesia in these 3 cases is unknown. The remaining patient (LM) be- came amnesic in 1984 as the result of a respiratory arrest that occurred during an epileptic seizure.

These 4 patients averaged 67.0 years of age at the time of the MR examination. They had an average of 14.3 years of education and a mean WAIS-R IQ of 111.0. Individual IQ scores and WMS-R index scores are shown in Table 1 . Immediate and delayed $(12 \mathrm{~min})$ recall of a short prose passage averaged 4.8 and 0 segments, respectively. Scores on other memory and cognitive tests are shown in Tables 2 and 3.

Control subjects. Six men served as a control group for the amnesic patients. They averaged 66.5 years of age, had an average of 15.8 years of education, and had an average WAIS-R IQ of 118.2. Individual IQ scores and WMS-R index scores are shown in Table 1 . Immediate and delayed recall of a short prose passage averaged 7.3 and 6.5 segments, respectively. Scores on other memory and cognitive tests are shown in Tables 2 and 3. All 6 control subjects had an MR examination of the HF. Four of them (JM, RC, JH, MB) also had an MR examination of the mammillary nuclei.

\section{Magnetic resonance studies}

All MR studies were conducted between November 1988 and December 1989 , using a 1.5-Tesla superconducting magnet (General Electric, Milwaukee). The MR sequences described below were completed either in 1 session or in 2 separate sessions on different days. The strategy was to use MR to examine selected brain regions with the highest possible resolution. In this way, we evaluated the possible involvement of these regions in amnesia.

Hippocampal formation. In an earlier investigation (Press et al., 1989), we determined that the optimal resolution of the hippocampus was obtained when the hippocampus was imaged precisely perpendicular to its long axis. Accordingly, the subject was first placed supine within the magnet, and the head was tilted to the posterior so that the line joining the lips and the external auditory canal was perpendicular to the examination table (and the longitudinal axis of the magnetic field). To show the long axis of the hippocampus and to help plan a coronal, highresolution sequence through the hippocampus, an initial, localizing sequence was conducted. T1-weighted images $(5 \mathrm{~mm}$ thick with a 2.5 - 
Table 2. Performance of subjects on standard tests of anterograde amnesia

\begin{tabular}{lclllll} 
Patient & $\begin{array}{c}\text { Dia- } \\
\text { gram } \\
\text { recall }\end{array}$ & $\begin{array}{l}\text { Paired } \\
\text { associates }\end{array}$ & $\begin{array}{l}\text { Word } \\
\text { recall }\end{array}$ & $\begin{array}{l}\text { Word } \\
\text { recog- } \\
\text { nition }\end{array}$ & $\begin{array}{l}50 \\
\text { words }\end{array}$ & $\begin{array}{l}50 \\
\text { faces }\end{array}$ \\
\hline Korsakoffs & & & & & & \\
RC & 3 & $0-0-3$ & $19 \%$ & $85 \%$ & 37 & 30 \\
DM & 0 & $0-0-2$ & $32 \%$ & $56 \%$ & 24 & 29 \\
PN & 2 & $1-1-1$ & $29 \%$ & $83 \%$ & 27 & 38 \\
JW & 4 & $0-0-2$ & $29 \%$ & $90 \%$ & 29 & 34 \\
$\quad$ Mean & 2.3 & $0.3-0.3-2.0$ & $27 \%$ & $79 \%$ & 29.3 & 32.8 \\
Non-Korsakoffs & & & & & \\
WH & 1 & $0-0-0$ & $40 \%$ & $84 \%$ & 29 & 24 \\
WI & 0 & $0-0-0$ & $29 \%$ & $85 \%$ & 31 & 30 \\
JL & 1 & $0-0-0$ & $40 \%$ & $93 \%$ & 31 & 20 \\
LM & 11 & $1-1-3$ & $44 \%$ & $98 \%$ & 30 & 37 \\
Mean & 3.3 & $0.3-0.3-0.8$ & $38 \%$ & $90 \%$ & 30.3 & 27.8 \\
Controls & & & & & & \\
MB & 13 & $1-9-10$ & $44 \%$ & $92 \%$ & - & - \\
RC & 15 & $8-9-10$ & $51 \%$ & $97 \%$ & - & - \\
WG & 9 & $3-2-4$ & $51 \%$ & $93 \%$ & - & - \\
JH & 13 & $7-10-10$ & $37 \%$ & $91 \%$ & - & - \\
NH & 16 & $7-9-10$ & $53 \%$ & $93 \%$ & - & - \\
JM & 20 & $7-10-10$ & $75 \%$ & $98 \%$ & - & - \\
Mean & 14.3 & $5.5-8.2-9.0$ & $52 \%$ & $94 \%$ & - & - \\
\hline
\end{tabular}

The diagram recall score is based on delayed $(12 \mathrm{~min})$ reproduction of the ReyOsterrieth figure (Osterrieth, 1944; maximum score, 36). The average score for copying the figure was 27.8 for the patients with Korsakoff's syndrome, 28.0 for the non-Korsakoff amnesic patients, and 31.2 for the control subjects. The paired associates score is the number of word pairs recalled on 3 successive trials (maximum score, $10 /$ trial). The word recall score is the percentage of words recalled out of 15 across 5 successive study-test trials (Rey, 1964). The word recognition score is the percentage of words identified correctly across 5 successive study-test trials (yes/no recognition of 15 new words and 15 old words). The score for words and faces is based on a 24-hr recognition test of 50 words or 50 faces (modified from Warrington, 1984; maximum score, 50; chance, 25 ). In a previous study (Squire and Shimamura, 1986), 8 normal subjects scored 41.1 for words and 38.1 for faces on this version of the test.

$\mathrm{mm}$ gap between images) were acquired in the sagittal plane centered at the midline [TR, $200 \mathrm{msec}$; TE, $20 \mathrm{msec}$; matrix, $256 \times 128$, field of view (FOV), $24 \mathrm{~cm}$; number of excitations (NEX), 1]. Following the localizing sequence, the head of the patient was repositioned slightly, if necessary, to orient the hippocampus appropriately, that is, so that its long axis was perpendicular to the coronal imaging plane. Positioning the patient's head in this way allowed us to obtain more sections than if the imaging plane had been determined by available software instead of by tilting the patient's head.

High-resolution coronal images were obtained using a T1-weighted sequence (TR, $400 \mathrm{msec}$; TE, $20 \mathrm{msec}$; matrix, $256 \times 256$; FOV, 16; NEX, 6). Additional options were selected as follows: saturation pulse, superior-inferior; frequency gradient direction, superior-inferior; suppression of wrap-around artifact in the frequency-encoding gradient direction. Six or 7 interleaved, 5 -mm-thick sections (with no interslice gaps) were acquired with $0.625-\mathrm{mm}$ in-plane spatial resolution. The most anterior section was acquired at approximately the caudal border of the pes hippocampus. With 6 or 7 sections, we were able to survey $30-35 \mathrm{~mm}$ of the hippocampus out of a total rostrocaudal length of about $40 \mathrm{~mm}$.

Mammillary nuclei. For most patients ( 8 of 12), images were acquired in the axial, coronal, and sagittal planes. For the remaining 4 patients (RC, PN, JW, and WI), images were acquired only in the axial and sagittal planes. Where possible, we attempted to obtain sections that were centered in the middle of the mammillary nuclei and/or in the middle of the right medial mammillary nucleus (in order to minimize volume averaging of the mammillary nuclei with adjacent structures and cerebrospinal fluid). A Tl-weighted axial sequence through the mammillary nuclei was usually performed first. The center section of this sequence was located so as to pass through the dorsoventral midline
Table 3. Performance of subjects on other cognitive tests

\begin{tabular}{llll} 
Patient & $\begin{array}{l}\text { Boston } \\
\text { Naming Test }\end{array}$ & $\begin{array}{l}\text { Word fluency } \\
\text { (FAS) }\end{array}$ & $\begin{array}{l}\text { Dementia } \\
\text { Rating } \\
\text { Scale (DRS) }\end{array}$ \\
\hline Korsakoffs & & & \\
RC & 56 & 51 & 125 \\
DM & 55 & 21 & 119 \\
PN & 56 & 36 & 131 \\
JW & 57 & 49 & 132 \\
Mean & 56.0 & 39.3 & 126.8 \\
Non-Korsakoffs & & & \\
WH & 58 & 57 & 130 \\
WI & 57 & 30 & 129 \\
JL & 48 & 46 & 130 \\
LM & 50 & 43 & 135 \\
Mean & 53.3 & 44.0 & 131.0 \\
Controls & & & \\
MB & 49 & 35 & 137 \\
RC & 57 & 33 & 143 \\
WG & 57 & 39 & 143 \\
JH & 56 & 33 & 139 \\
NH & 58 & 30 & 143 \\
JM & 58 & 55 & 144 \\
Mean & 55.8 & 37.5 & 141.5 \\
\hline
\end{tabular}

The Boston Naming Test (Kaplan et al., 1983) assesses the ability to name 60 drawings of objects (maximum score, 60). The score for the Controlled Word Association Test (FAS) (Renton, 1973) is the total number of words that could be generated beginning with the letters $F, A$, and $S(1-$ min time limit for each letter). The Dementia Rating Scale (Mattis, 1976) assesses a spectrum of cognitive functions, including memory, attention, initiation and perseveration, construction and conceptualization (maximum score, 144 points). The patients with Korsakoff's syndrome lost most of their points on the memory ( 8.0 points) and the initiationperseveration (5.0 points) subportions of the test. The non-Korsakoff amnesic patients lost most of their points on the memory subportion of the test ( 9.8 points).

of the mammillary nuclei as identified in the sagittal localizing sequence. Eight interleaved, 3-mm-thick sections (with no interslice gaps) were acquired (TR, $400 \mathrm{msec}$; TE, $20 \mathrm{msec}$; matrix, $256 \times 256$; FOV, 16 $\mathrm{cm}$; NEX, 4), with additional options as follows: saturation pulse, inferior only; frequency gradient direction, anteroposterior; suppression of wrap-around artifact in the frequency and phase-encoding gradient directions. Images from this series were used to measure the mediolateral and anteroposterior diameters of the medial mammillary nuclei.

To obtain coronal images, the middle section of the sequence was located at the center of the mammillary nuclei, as observed in an earlier imaging sequence. These $\mathrm{T} 1$-weighted images were also $3 \mathrm{~mm}$ thick and interleaved (TR, $400 \mathrm{msec}$; TE, $20 \mathrm{msec}$; matrix $256 \times 256$; FOV, 16 $\mathrm{cm}$; NEX, 4). Additional options were as follows: saturation pulse, superior and inferior; frequency gradient direction, superior-inferior; other options, samc as for axial scquencc, abovc. Images from this scrics were used to measure the dorsoventral and mediolateral diameters of the medial mammillary nuclei.

Finally, to obtain high-resolution sagittal images, T1-weighted images were acquired as described above (TR, $400 \mathrm{msec}$; TE, $20 \mathrm{msec}$; matrix, $256 \times 256$; FOV, $16 \mathrm{~cm}$; NEX, 4). Where possible, the middle section of the sequence was located at the center of the right mammillary nucleus, as observed in an earlier imaging sequence. Additional options were as follows: saturation pulse, superior and inferior; frequency gradient direction, anteroposterior; other options, same as for axial sequence, above. Images from this series were used to measure the dorsoventral and anteroposterior diameters of the mammillary nuclei.

Brain. To examine the brain for regions of abnormal morphology and/or signal intensity, 1 additional T2-weighted sequence was performed. These images were $5 \mathrm{~mm}$ thick with 0 - or $2.5-\mathrm{mm}$ interslice gaps (TR, 2000-3000 msec; TE, 25 or 30 and 70 or $80 \mathrm{msec}$; matrix, $256 \times 256$; FOV , $16-20 \mathrm{~cm}$; NEX, 1). Additional options were as follows: for axial sequences - saturation pulse: inferior only, frequency gradient direction: anteroposterior, flow compensation: ON; for coronal sequences-saturation pulse: superior and inferior, frequency gradient 


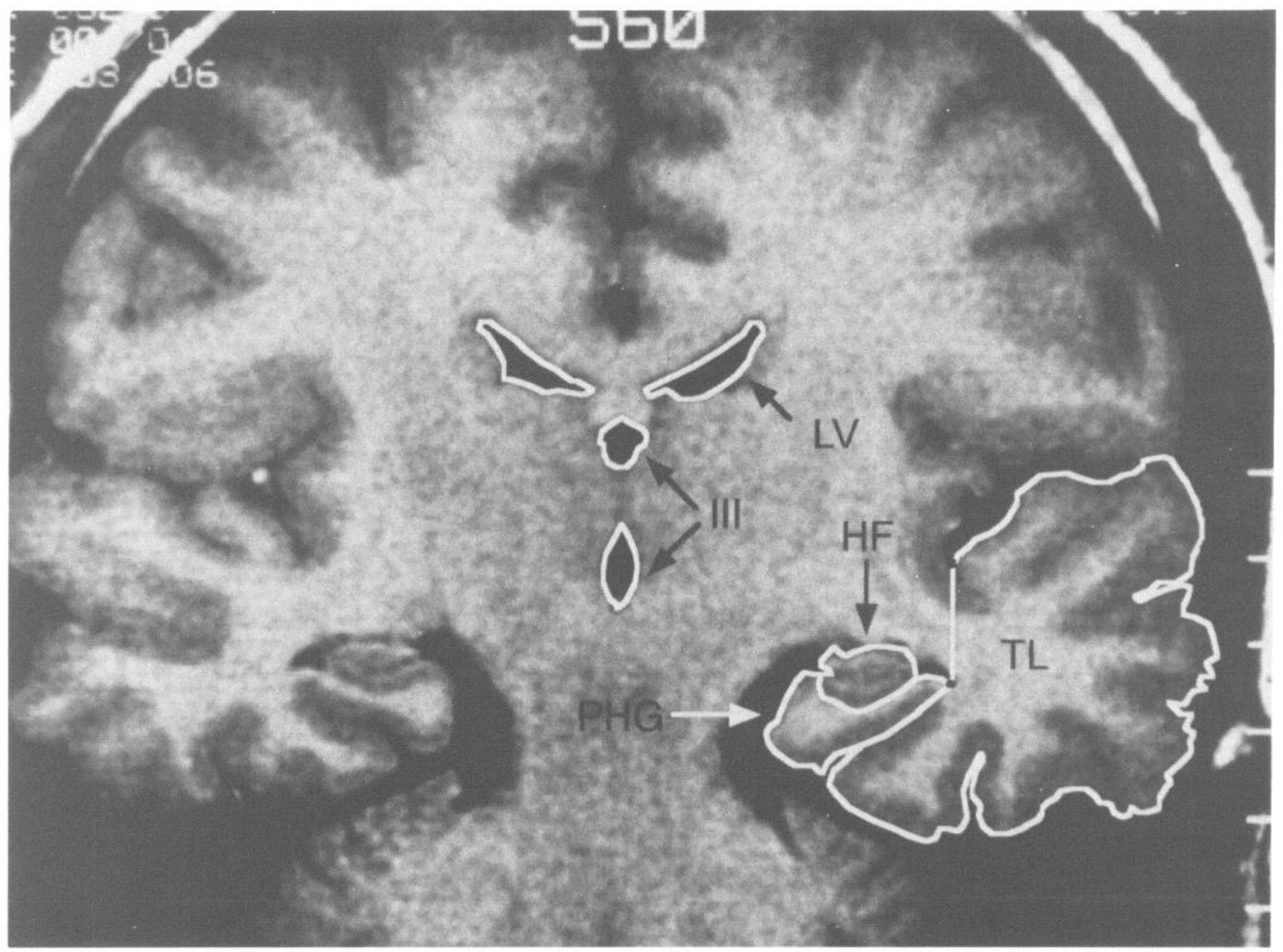

Figure 1. Coronal T1-weighted image from a normal young adult. The image indicates the outlines used to make the temporal lobe and ventricular measurements. In the temporal lobe, all profiles began at the lateral ventricle adjacent to the HF (lower black dot). The fundus of the inferior limiting sulcus is indicated with the upper black dot. TL, temporal lobe; HF, hippocampal formation; PHG, parahippocampal gyrus (white arrow); $\mathrm{LV}$, lateral ventricle; III, third ventricle. The scale bar at right is in 1 -cm divisions.

direction: superior-inferior, flow compensation: OFF. This sequence provided coronal images from the frontal through the occipital lobes in 10 subjects (all except Korsakoff patients PN and DM and control subjects $\mathrm{MB}$ and $\mathrm{JH}$ ). In addition, axial images were obtained from the vertex through the level of the medulla in 5 of these same subjects, as well as in PN and DM. The 2 control subjects did not undergo a T2weighted imaging sequence.

In summary, all 14 subjects had a T1-weighted sequence focusing on the HF. Twelve subjects (i.e., all but 2 control subjects) had additional T1-weighted sequences focusing on the mammillary nuclei. Finally, all but 2 control subjects also had a T2-weighted sequence to examine the brain.

Image analysis: temporal lobe and hippocampal formation. Area measurements of the HF, parahippocampal gyrus, and temporal lobe were conducted as previously described (Press et al., 1989). Measurements were made using the first section caudal to the pes hippocampus and the 2 adjacent caudal sections. Figure 1 illustrates the regions included in each of the temporal lobe measurements. The average area of each region of interest on both sides was measured across the 3 sections; that is, 3 areas were averaged on each side. For all measurements, the region of interest was traced directly from the radiographic image at a magnification of 3.6 $\times$ using an Aus Jena microfilm viewer (Dokumator DL 2 ). The outline of each region of interest was then entered into a microcomputer using a Hitachi digitizing tablet, and the area was computed using commercially available software (Sigma-Scan).

The outline of the HF extended from the lateral limit of the lateral ventricle adjacent to the $\mathrm{HF}$ and extended medially to encompass the fimbria, dentate gyrus, hippocampus proper, and subiculum (Fig. 1).

Figure 2. T1-weighted images through 1 level of HF from subjects in each of 3 groups. Four of the control subjects $(C O N)$ are illustrated in column 1, the 4 non-Korsakoff amnesic patients $(A M N)$ are illustrated in column 2, and the 4 amnesic patients with Korsakoff's syndrome (KOR) are illustrated in column 3. The initials of each subject are in the lower left hand corner of each panel. In the far right column, photographic enlargements of the left $\mathrm{HF}$ are shown for 1 control subject $(R C$, top panel), 1 non-Korsakoff amnesic patient (WI, middle panel) and 1 patient with Korsakoff's syndrome ( $\mathrm{JW}$, bottom panel). The scale bar at the right of each image is in 1-cm divisions. Note the markedly shrunken appearance of the HF in the non-Korsakoff amnesic patients and the relatively larger and similar appearance of this region in the control subjects and in the patients with Korsakoff's syndrome. Asterisks in the upper left panel of column 1 indicate the position of the hippocampus on each side. 

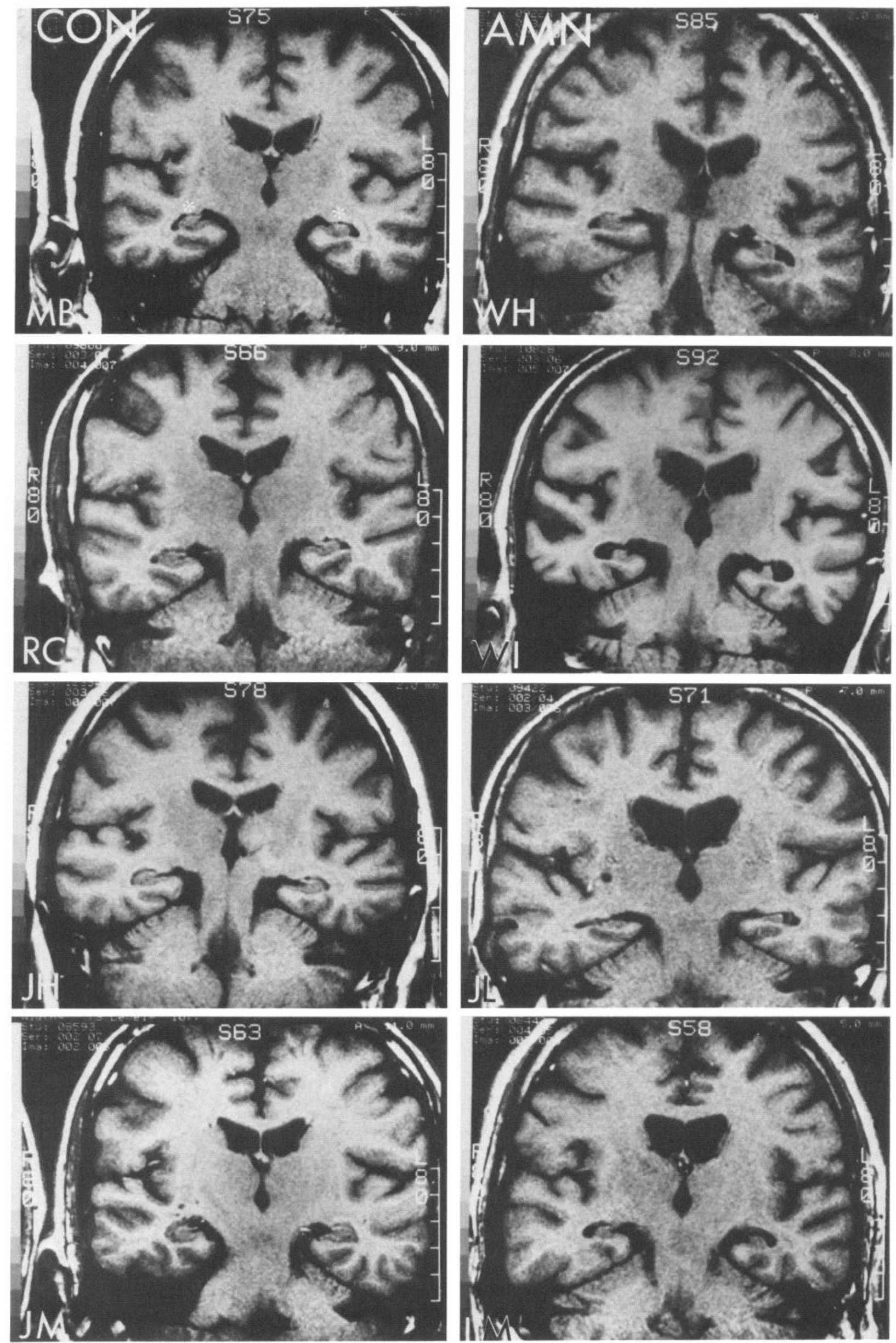

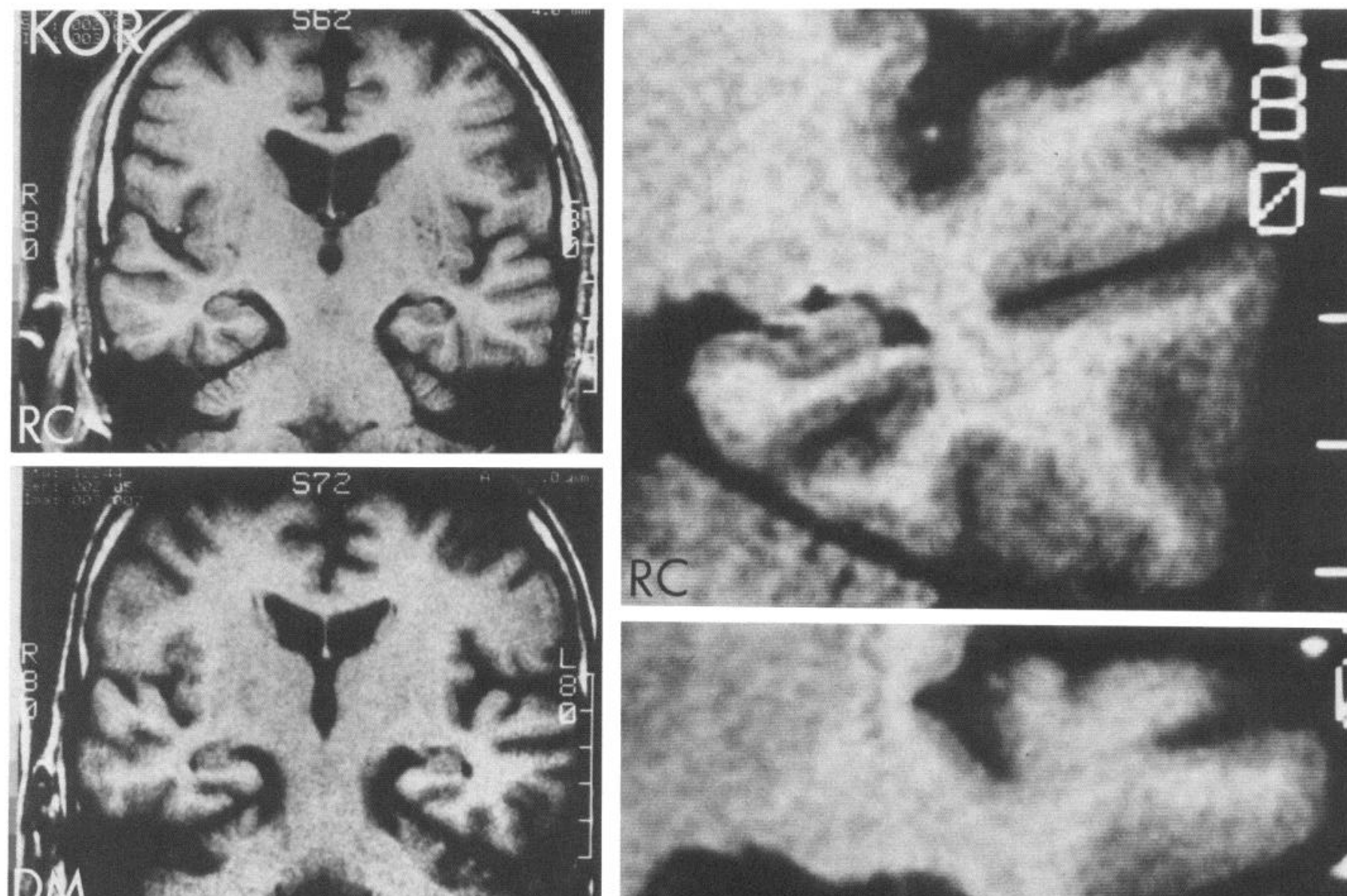

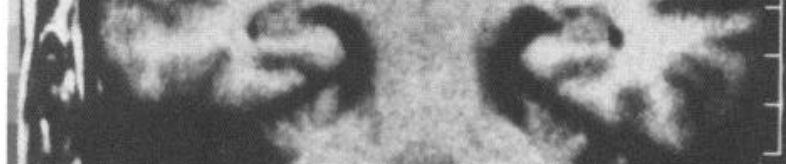
bin 3
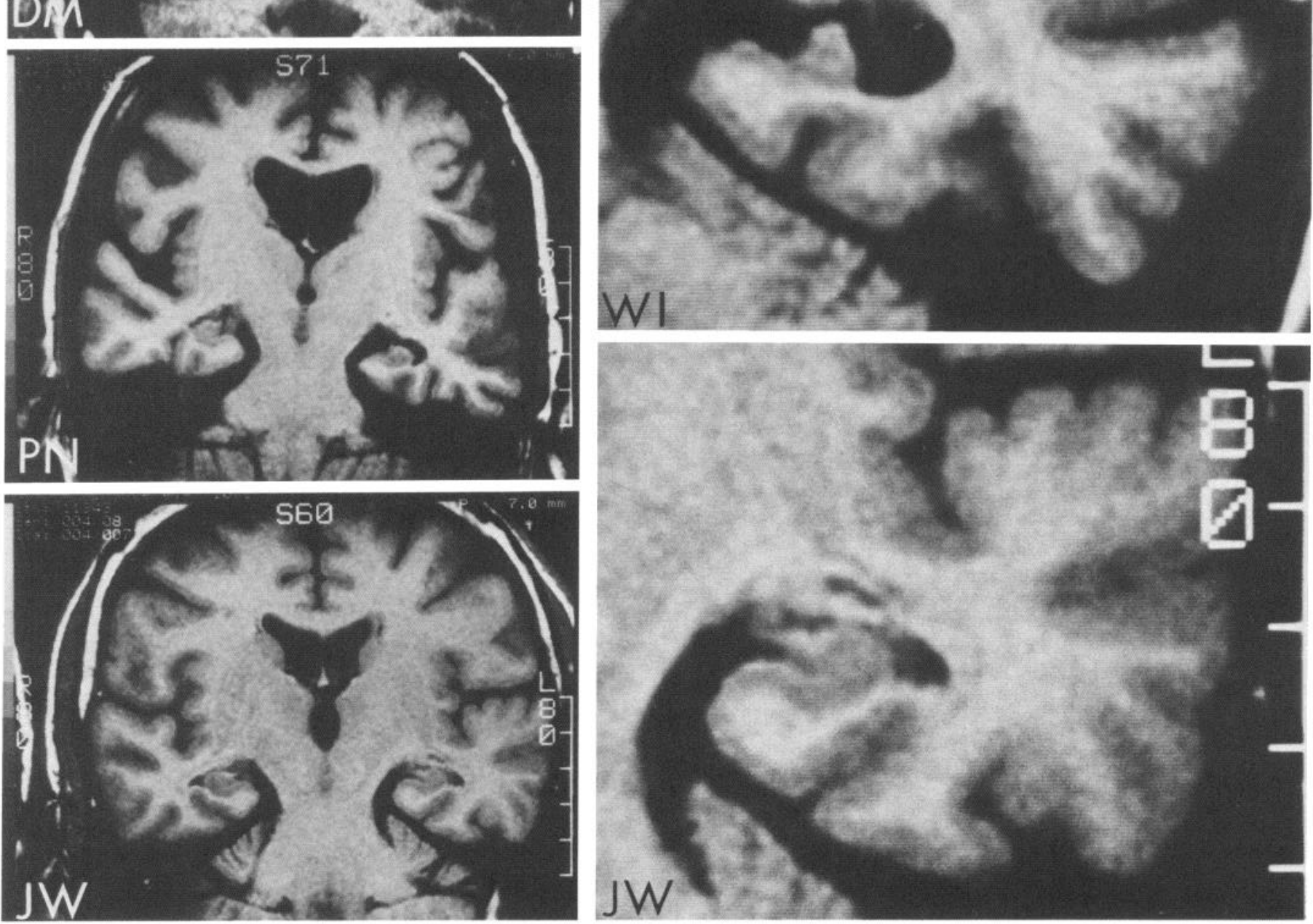

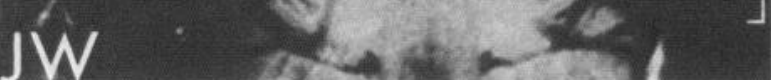

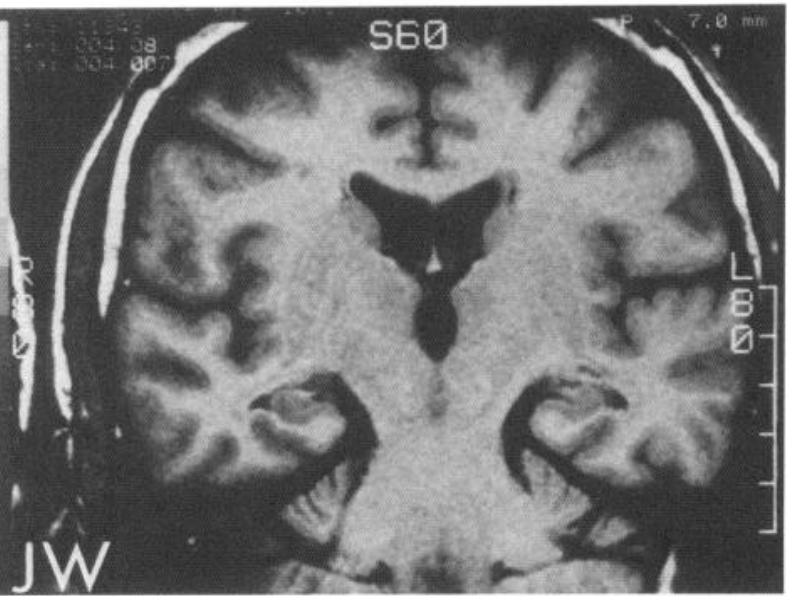

JW 

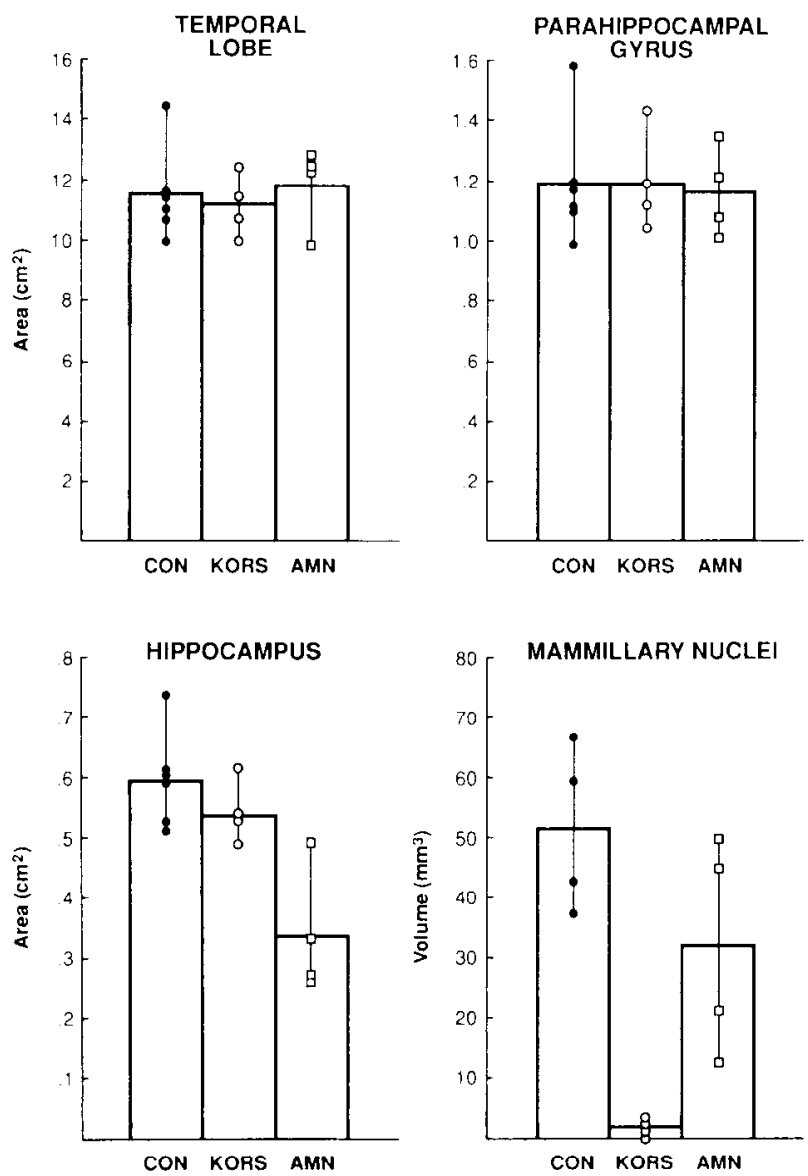

Figure 3. Size of 4 brain regions determined from MR images. Symbols show values for individual subjects, averaged between the left and right sides of the brain. Only 4 control subjects contributed to the measurements of the mammillary nuclei. For the hippocampal measurements, the non-Korsakoff amnesic patients (from the largest to the smallest values) are WH, WI, LM, and JL. For the measurements of mammillary nuclei, the order is WI, LM, WH, and JL. For the patients with Korsakoff's syndrome, the order for the hippocampal measurements is JW, RC, DM, and PN; for the mammillary nuclei, the order is JW, RC, PN, and DM. CON, age-matched control subjects; KORS, amnesic patients with Korsakoff's syndrome; $A M N$, other amnesic patients.

The area of the parahippocampal gyrus was measured by digitizing a profile that extended from the same point on the lateral ventricle used for the hippocampal measurement to the fundus of the collateral sulcus. The profilc was then closed between the beginning and ending points. Finally, to obtain the area of the parahippocampal gyrus alone, the area previously calculated for the HF was subtracted from the area within the profile.

The outline for the temporal lobe measurement began at the same point on the lateral ventricle that was used for the 2 measures described above. The outline then extended to the fundus of the collateral sulcus, around the temporal cortex to the inferior limiting sulcus of the insular cortex, and back to the starting point on the lateral ventricle. The outline of the temporal lobe followed the cortical surface into the sulci; the values obtained were therefore independent of the extent of the sulcal prominence. The areas of the left and right bodies of the lateral ventricle were measured in the same 3 sections used for the temporal lobe measurements. The area of the third ventricle was measured in the 2 rostral sections.

Image analysis: mammillary nuclei. We attempted to draw the outline of the right and left medial mammillary nuclei in all 3 planes of image acquisition. Where possible, the prominent capsule of fibers that ensheaths the medial mammillary nucleus was used to indicate the nuclear boundary. When portions of the perimeter of the medial mammillary nucleus were not clear, the perimeter was completed on the assumption that the nucleus was a smooth ovoid. On several occasions, and particularly for the patients with Korsakoff's syndrome, the image of the medial mammillary nucleus on one or the other sides of the brain was not sufficiently clear to draw an outline with confidence. However, because duplicate measures of diameter for each dimension were potentially available from the 3 planes of sections, that is, measurements for 2 dimensions can be obtained from each of the 3 planes, it was usually possible to obtain at least 1 reliable measurement in each dimension.

Following the strategy outlined by Charness and DeLaPaz (1987), we computed the volume of the medial mammillary nuclei rather than their average areas. The mammillary nuclei were assumed to have an ellipsoid shape, and their volume was calculated using the formula, $\mathrm{V}$ $=(4 / 3)(\pi a b c)$, where $a, b$, and $c$ are the radii of each mammillary nucleus in the dorsoventral, mediolateral, and anteroposterior dimensions, respectively. From each imaging series, sections were identified in which each medial mammillary nucleus appeared the largest. For each mammillary nucleus so identified, 2 axes were drawn and measured using the microcomputer and software described above. In each case, we attempted to measure the longest axis in each dimension, for a maximum of 6 measurements for each mammillary nucleus ( 2 axes measured in each of 3 planes). Where duplicate measurements were available for one of the dimensions, they were averaged to obtain 1 measurement for each dimension.

\section{Results}

The average area of the temporal lobe was nearly identical in the 3 groups (Figs. 2, 3). For the left temporal lobe, the mean area was $11.24,11.40$, and $11.22 \mathrm{~cm}^{2}$ for the normal, nonKorsakoff amnesic, and Korsakoff patients, respectively. For the right temporal lobe, the corresponding values were 11.80 , 12.13 , and $11.17 \mathrm{~cm}^{2}$. It should be noted that the right temporal lobes in patients PN (Korsakoff) and WI (non-Korsakoff amnesic) were smaller in area (3.6 and 6.6\%, respectively) than the smallest control value.

In contrast, the HF was markedly reduced in size in the amnesic patients (controls: left $\mathrm{HF}=0.56 \mathrm{~cm}^{2}$, right $\mathrm{HF}=0.63$ $\mathrm{cm}^{2}$; non-Korsakoff amnesics: left $\mathrm{HF}=0.33 \mathrm{~cm}^{2}$, right $\mathrm{HF}=$ $0.35 \mathrm{~cm}^{2}$; Korsakoff patients: left $\mathrm{HF}=0.53 \mathrm{~cm}^{2}$, right $\mathrm{HF}=$ $0.55 \mathrm{~cm}^{2}$ ). The area of the HF in the non-Korsakoff amnesic patients was $57 \%$ of that in the control subjects $(t[8]=4.37, p$ $<0.01)$ and $63 \%$ of that in the Korsakoff patients $(t[6]=3.39$, $p<0.02$ ). The HF in the patients with Korsakoff's syndrome was $90 \%$ of normal size $(p>0.10)$. The results were the same when the area of the HF was calculated as a percentage of the size of the temporal lobe. For the control subjects, this percentage averaged 5.2\% (range, 4.7-5.7\%); for the non-Korsakoff amnesic patients, this percentage averaged $2.9 \%(\mathrm{JL}, 2.0 \%$; LM, $2.2 \%$; WI, $3.5 \%$; WH, $4.0 \%$; for patients with Korsakoff's syndrome, the average was $4.9 \%$ (range, $4.2-5.3 \%$ ). The non-Korsakoff amnesic patient with the largest $\mathrm{HF}\left(\mathrm{WH}, 0.49 \mathrm{~cm}^{2}\right)$ also had a relatively large temporal lobe $\left(12.3 \mathrm{~cm}^{2}\right)$.

The area of the parahippocampal gyrus was similar in the 3 groups (Fig. 3). The same finding was obtained when the area of the parahippocampal gyrus was calculated as a percentage of the size of temporal lobe (controls, 10.4\%; non-Korsakoff amnesics, 9.9\%; Korsakoffs, $10.7 \%$ ). The only exception to this finding was patient JL, whose parahippocampal gyrus was only $7.9 \%$ of the size of his temporal lobe. The next smallest value $(9.3 \%)$ was observed in a normal subject.

The lateral ventricles and the third ventricle (Fig. 4) were larger in both patient groups than in the control subjects (lateral ventricles-Korsakoff patients vs controls: $t[8]=2.27, p=0.053$; non-Korsakoff amnesics vs controls: $t[8] 3.01, p<0.02$; third ventricle-Korsakoff patients vs controls: $t[8]=1.97, p=0.08$; non-Korsakoff amnesics vs controls: $t[8]=2.88, p<0.05$ ). 


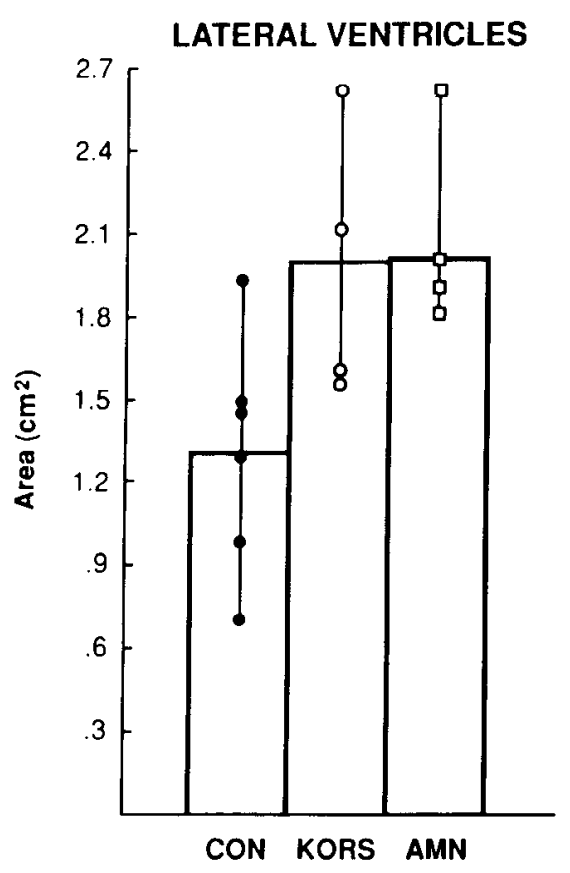

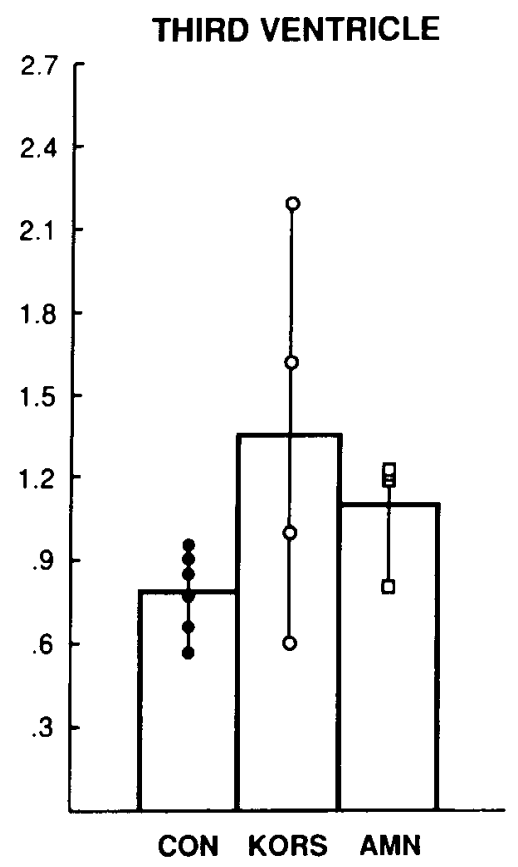

Figure 4. Size of lateral ventricles and third ventricle determined from MR images. Symbols show values for individual subjects. For the lateral ventricle measurements, the patients with Korsakoff's syndrome (from the largest to the smallest values) are PN, RC, DM, and JW. The order for the non-Korsakoff amnesic patients is JL, LM, WI, and WH. For the third ventricle measurements, the order for the patients with Korsakoff's syndrome is RC, DM, $J W$, and PN. For the non-Korsakoff amnesic patients, the order is WI, LM, $\mathrm{JL}$, and WH. CON, age-matched control subjects; KORS, amnesic patients with Korsakoff's syndrome; $A M N$, other amnesic patients.
Ventricle size did not differ between the Korsakoff patients and the non-Korsakoff amnesic patients $(p>0.10)$.

Figure 5 shows the mammillary nuclei in all 3 imaging planes for a representative subject in each group. For the 4 control subjects who underwent this protocol, the mammillary nuclei averaged $51.4 \mathrm{~mm}^{3}$ in volume (range, 37.4-66.6 $\mathrm{mm}^{3}$; Fig. 3). This value closely corresponds to the value reported in an earlier study of 37 normal subjects $\left(51.7 \mathrm{~mm}^{3}\right.$; Charness and DeLaPaz, 1987). It was usually possible to visualize both mammillary nuclei in all 3 imaging planes, thereby obtaining 2 independent measures for the radius of each nucleus in each of the $3 \mathrm{di}$ mensions (antcroposterior, dorsoventral, and mediolateral). However, on 3 imaging sequences out of a total of 12, one or the other of the mammillary nuclei could not be detected. As a result, for some patients in some dimensions, the radius of one of the mammillary nuclei was based on 1 measurement instead of 2 .

The average volume of the mammillary nuclei was modestly, but not signinicantly, reduced in size in the non-Korsakof amnesic patients $(t[6]=1.72, p>0.10)$. It appeared that 2 of the patients had mammillary nuclei of approximately normal volume (LM, $44.6 \mathrm{~mm}^{3}$; WI, $49.5 \mathrm{~mm}^{3}$ ), and 2 had small mammillary nuclei (WH, $\left.21.2 \mathrm{~mm}^{3} ; \mathrm{JL}, 13.1 \mathrm{~mm}^{3}\right)$. Indeed, these latter 2 volumes were more than 2 standard deviations below the mean control value. With 1 exception (WH), it was possible to visualize both mammillary nuclei in at least 2 and sometimes in all 3 of the imaging planes. WH's left mammillary nucleus was detected only in the coronal plane. This image provided radii for 2 dimensions. For the purpose of computing volume, the larger of these 2 measurements was taken as the radius for the missing dimension.

In the patients with Korsakoff's syndrome, the mammillary nuclei were difficult to visualize. When tissue could be detected in the appropriate location, it could not be identified as mammillary nuclei with the same confidence as it could in the normal subjects or in the non-Korsakoff amnesic patients. In one patient (DM), the mammillary nuclei could not be detected in any of the 3 imaging planes. In the other 3 patients, the mammillary nuclei could be detected in only 1 plane, and in 2 of these patients, only 1 mammillary nucleus was detected. As described above, images from 1 plane provide radii for 2 dimensions, and the larger of these 2 measurements was taken as the radius for the missing dimension. The average volume of the mammillary nuclei for the patients with Korsakoff's syndrome was $1.94 \mathrm{~mm}^{3}$, markedly smaller than the corresponding volumes for the other 2 groups (Korsakoff patients vs controls: $t[6]=7.17, p<0.001$; Korsakoff patients vs non-Korsakoff amnesic patients: $t[6]=$ $3.40, p<0.02$ ).

The $\mathrm{T} 2$-weighted images revealed some additional abnormalities. Three of the 4 non-Korsakoff amnesic patients had hyperintense white-matter foci, similar to those frequently observed in the elderly (Braffman et al., 1988). These are considered to result from chronic vascular insufficiency and/or small infarctions. Their frequency on MR examinations increases in individuals with hypertension or other cardiovascular risk factors, especially those with both risk factors and symptoms of cerebrovascular disease, such as transient ischemic attacks (Gerard and Weisberg, 1986). Patient WH had moderately severe white-matter abnormalities (e.g., hyperintense foci) in the striatum and mildly abnormal findings in the region of the lateral ventricles. Lesions with similar characteristics were also observed in the pons. Patient WI had moderately severe focal white-matter abnormalities, subcortically and around the lateral ventricles. Patient JL had the most severe white-matter abnormalities, which were mostly distributed subcortically. He also had the most severe sulcal widening, especially in the frontal and parietal lobes. Finally, he had an apparently benign subependymal cyst in the left thalamus at the border of the third ventricle.

Among the 4 patients with Korsakoff's syndrome, 3 had hyperintense foci. Patient PN had moderately severe focal whitematter abnormalities subcortically and about the lateral ventricles. Patient JW had mild white-matter abnormalities in these same regions. Patient RC had similar bilateral foci in the 

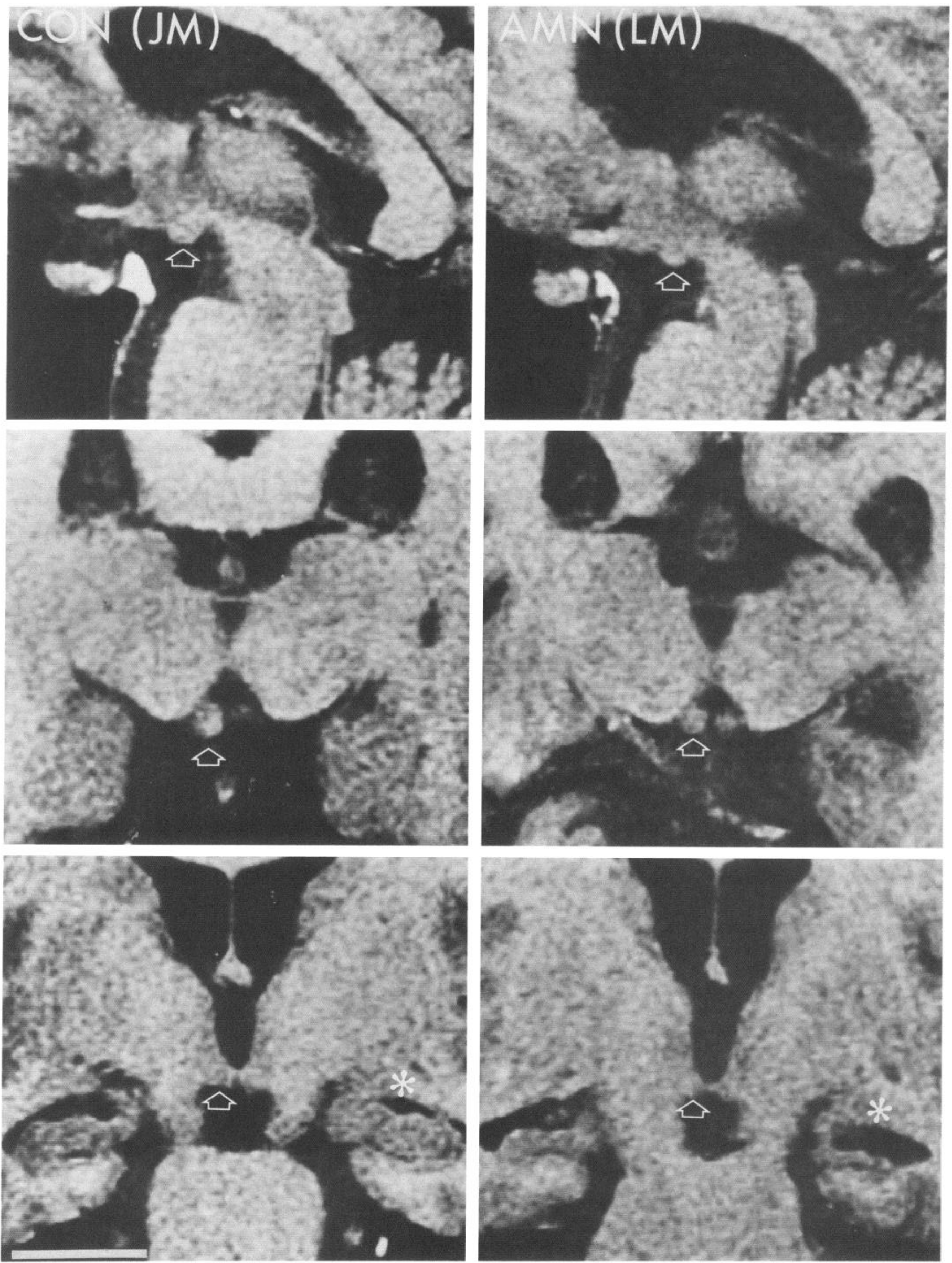

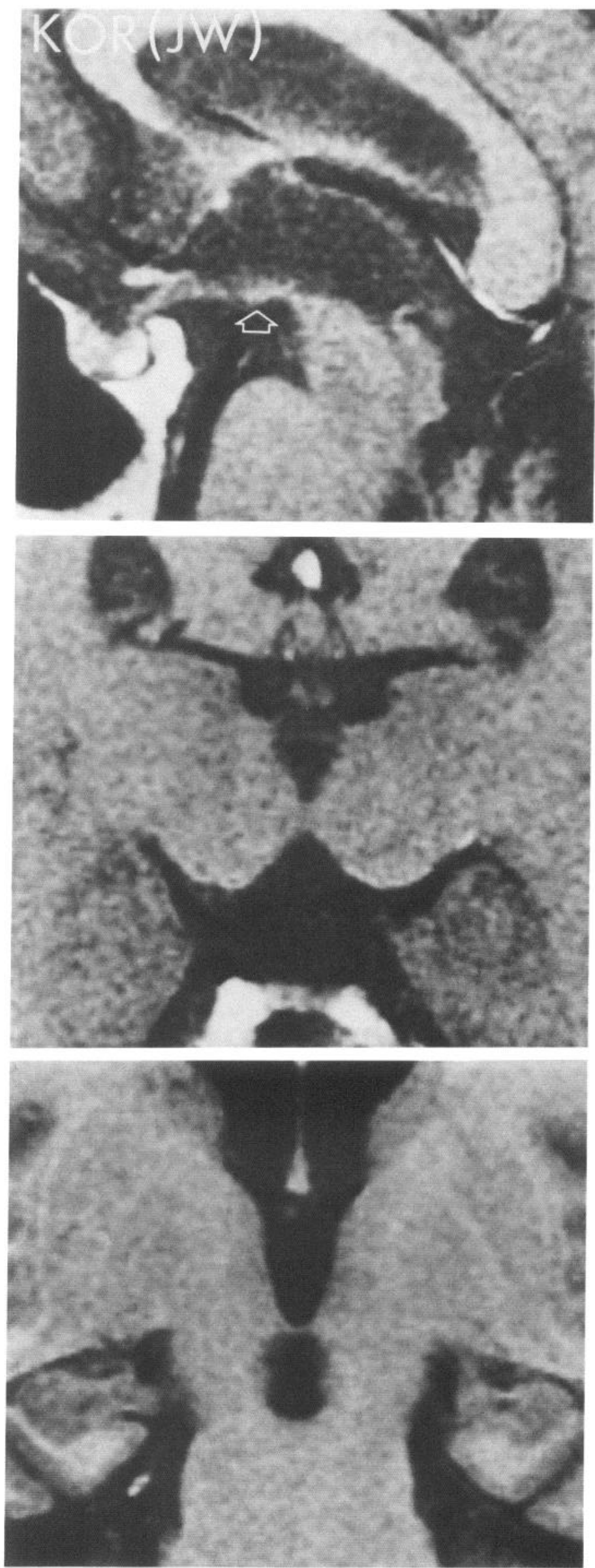

pons. Finally, 3 of the patients in this group (DM, PN, and JW) had noticeable loss of cerebellar volume, particularly in the anterior lobe, as has been commonly observed in alcoholism (Victor et al., 1989).

Among the control subjects, only 1 (WG) had evidence of hyperintense white-matter foci (in this case, mild abnormalities in the striatum and in the vicinity of the lateral ventricles).

\section{Discussion}

The MR findings provide unambiguous information about neuroanatomical changes associated with memory impairment in our patients. The amnesic patients with Korsakoff's syndrome had abnormally small mammillary nuclei that were barely detectable in most cases. This finding agrees with the conclusion from a large body of neuropathological literature that patients with Wernicke-Korsakoff's syndrome invariably have bilateral lesions of the mammillary nuclei (for review, see Victor et al., 1989). For the group with Korsakoff's syndrome, the average values for the temporal lobes, HF, and parahippocampal gyri were normal. Although the average group values were normal, the relatively small size of these structures in patient PN raises the possibility that a certain degree of global atrophy may be present in some patients with Korsakoff's syndrome.

These negative findings cannot rule out the possibility that more subtle abnormalities might be present in the medial temporal region of these patients, for example, losses from cell fields of the hippocampus insufficient to alter substantially the area of the structure. (It is important to note here that, in both patient groups, the measured components of the ventricular system were larger than in the control subjects. This finding suggests that some minor loss of brain tissue has occurred in the patients, presumably in addition to that measured in the HF and mammillary nuclei.) In 2 neuropathological studies of Korsakoff's syndrome involving 4 patients who had been carefully studied during life (Mair et al., 1979; Mayes et al., 1988), bilateral damage was observed in the mammillary nuclei and medial thalamus. Of the 2 patients studied with quantitative methods, 1 had some bilateral cell loss from the CA1 region of the hippocampus (BC; Mayes et al., 1988). In the 2 patients examined qualitatively, the hippocampus was considered to be normal. Victor et al. (1989) reported that the hippocampus was involved in 8 of 22 patients with a diagnosis of Wernicke-Korsakoff's disease (his Table 6-8, p. 87). Twenty-three cases were also available in which the symptoms of Korsakoff's syndrome had been recognized during life (Victor et al., 1989, Table 8-1, p. 120). According to Victor (M. Victor, unpublished observa-

Figure 5. T1-weighted images of mammillary nuclei for 1 subject in each group. The top panel shows a sagittal section, the middle panel shows an axial section, and the bottom panel shows a coronal section. For each subject, the selected section contained the largest image of the medial mammillary nucleus. The open arrow points to 1 of the mammillary nuclei in each panel in which mammillary nuclei are visible. In the control subjects and non-Korsakoff amnesic patients, the mammillary nuclei were easily visible. In the patients with Korsakoff's syndrome, however, the mammillary nuclei could not generally be detected with confidence. The illustrated patient (JW) had the largest mammillary nucleus in this group, which was detectable only on 1 side of the brain and only in the sagittal sections (open arrow, top panel). No mammillary nuclei could be detected for JW in the axial and coronal sections. White asterisks in lower panels are above the hippocampal formation. Note shrunken appearance of this region in patient LM. The scale bar at the lower left equals $2 \mathrm{~cm}$ and applies to all panels in this figure. 
tions), in 11 of these cases where the hippocampus was examined, 7 had no discernible abnormalities, and 4 had microscopic lesions that did not substantially affect the hippocampal cell fields. These lesions were not considered significant enough to have contributed to the memory impairment. Finally, in a semiautomated MR study of patients with Korsakoff's syndrome (Jernigan et al., 1989), a small but significant reduction in volume of gray matter (13\%) was reported for a sector of medial and posterior-inferior cortex, which appears to include the hippocampus, parahippocampal gyrus, and other adjacent cortices, including the insula. It is difficult to relate this finding to the structures that were measured in the present study. To summarize, in Korsakoff's syndrome, pathology of the HF appears to be minor and inconsistent and is therefore unlikely to be associated with the memory impairment.

The findings in the non-Korsakoff amnesic patients were the reverse of those in the patients with Korsakoff's syndrome. The $\mathrm{HF}$ was markedly reduced in size in all 4 patients. In addition, the parahippocampal gyrus was abnormally small in 1 patient (JL). The mammillary nuclei were substantially reduced in volume in 2 patients but were of normal volume in the other 2 . It is useful to note, in this context, that reductions in the volume of the mammillary nuclei (about $40 \%$ ) were also observed in a recent study of monkeys with bilateral lesions of the $\mathrm{HF}$ (Zola-Morgan et al., 1989). In monkeys, reduced volume of the mammillary nuclei was presumably a consequence of the deafferentation sustained by the medial mammillary nuclei after elimination of their input from the subiculum. Accordingly, it is possible that those non-Korsakoff amnesic patients with small mammillary nuclei have more extensive damage to the HF (i.c., damage that includes the subiculum or the alveus) than patients with normal-sized mammillary nuclei. In any case, the mammillary nuclei of all 4 non-Korsakoff amnesic patients were substantially larger than those in any of the patients with Korsakoff's syndrome. Thus, despite the fact that reductions in the volume of the mammillary nuclei can occur both in patients with Korsakoff's syndrome and in non-Korsakoff amnesic patients with prominent hippocampal pathology, information about the volume of the mammillary nuclei helps to distinguish these 2 groups.

Three of the patients with Korsakoff's syndrome (DM, PN, and JW) also participated in a recent quantitative CT study that revealed significant reductions in thalamic tissue density (Shimamura et al., 1988). Although these changes were neither visually apparent in the CT scans nor apparent in our visual analysis of the MR scans, they were detected in CT using a semiautomated computer algorithm. Thus, for 3 of the patients with Korsakoff's syndrome in the present study, there is evidence for both thalamic damage and for hypothalamic damage in the mammillary nuclei.

Importantly, monkeys with bilateral lesions limited to the mammillary nuclei do not exhibit severe or long-lasting memory impairment (Aggleton and Mishkin, 1985; Zola-Morgan et al., 1989) on the same tests that are failed by monkeys with other medial temporal or diencephalic lesions, including lesions of the medial thalamus (Aggleton and Mishkin, 1983a, b). Therefore, though the mammillary nuclei are severely and invariably damaged in Korsakoff's syndrome, it is very unlikely that damage to the mammillary nuclei alone is responsible for the memory impairment. Rather, the findings from our patients and from other studies (for reviews, see Markowitsch, 1988; Victor et al., 1989 ) suggest that combined medial thalamic and mammillary nuclei damage occurs in Korsakoff's syndrome and that the memory impairment is due either to the combined damage or to the medial thalamic damage alone.

Although there are too few patients in each group for detailed within-group comparisons, the MR findings seem to be in general agreement with the neuropsychological findings, which provide information about the severity of memory impairment. First, among the patients with Korsakoff's syndrome, patient DM was the only one whose mammillary nuclei were undetectable in any plane. DM is also the most severely amnesic patient in this group (Tables 1,2). The other 3 patients are difficult to rank with respect to their memory impairment. Interestingly, patient DM also had the lowest thalamic density value of the 3 paticnts who participated in our earlier CT study (Shimamura et al., 1988).

Among the patients with non-Korsakoff amnesia, LM is the least impaired. His parahippocampal gyrus and mammillary nuclei are also of normal size. The other 3 patients are difficult to rank with respect to memory impairment, though WH may well be the most severely affected. Only WH and JL have abnormally small mammillary nuclei, which implies that WH and JL have damage to the HF (e.g., in the subicular complex) that is not present in the other 2 patients. JLalso has a small parahippocampal gyrus. Finally, among the non-Korsakoff amnesic patients, JL is the patient with the most severe and widespread sulcal prominence as judged by a survey of T2-weighted axial images of the entire brain. He also had the greatest degree of ventricular dilatation and the most severe white-matter abnormalities. These findings might not relate specifically to memory impairment, but they may account for JL's low score on the Boston Naming Test, which is sensitive to left cortical damage.

Whereas the present MR findings show unambiguously 2 different kinds of pathological changes in 2 identified patient groups with memory impairment, it remains unclear to what extent diencephalic and medial temporal lobe pathology produce noticeably or qualitatively different patterns of memory impairment (for 2 points of view, see Parkin, 1984; Victor et al., 1989). Although one would expect that the brain regions damaged in the 2 groups must make different contributions to normal memory, each region may also be a critical component of a larger functional system. Certainly, there are many similarities between diencephalic and medial temporal lobe amnesia. The issue of possible differences remains an important topic for study.

Much work on amnesic patients during the past several decades has been, of necessity, an exercise in cognitive analysis. This work has yielded much useful information about the organization of normal memory functions. The development of innovative neuroimaging techniques and high-resolution protocols now makes it possible to obtain unambiguous anatomical information relevant to the crucial issue of patient classification. Such information provides a foundation for exploring possible quantitative and qualitative differences between patients.

\section{References}

Aggleton JP, Mishkin M (1983a) Visual recognition impairment following medial thalamic lesions in monkeys. Neuropsychologia 21: 189-197.

Aggleton JP, Mishkin M (1983b) Memory impairments following restricted medial thalamic lesions in monkeys. Exp Brain Res 52:199209.

Aggleton JP, Mishkin M (1985) Mammillary-body lesions and visual recognition in the monkey. Exp Brain Res 58:190-197.

Baddeley $\Lambda$ (1982) Implications of ncuropsychological cvidence for 
theories of normal memory. In: Philosophical transactions of the royal society of london, Vol. 298 (Broadbent DE, Weiskrantz L, eds), pp 59-72. London: The Royal Society.

Benton AL (1973) The measurement of aphasic disorders. In: Aspectos patologicos del lengage (Caceres Velasquez A, ed). Lima: Centro Neuropsicologico.

Braffman BH, Zimmerman R, Trojanowski J, Gonatas N, Hickey W, Schlaepfer W (1988) Brain MR: pathologic correlation with gross and histopathology. II. Hyperintense white-matter foci in the elderly. Am J Neuroradiol 9:629-636.

Brierley JB (1977) Neuropathology of amnesic states. In: Amnesia (Whitty CWM, Zangwill OL, eds), pp 199-223. London: Butterworths.

Butters N, Cermak L (1980) Alcholic Korsakoff's syndrome, an information processing approach to amnesia. New York: Academic.

Butters N, Salmon D, Cullum M, Cairns P, Troster A, Jacobs D, Moss $M$, Cermak L (1988) Differentiation of amnesic and demented patients with the WMS-R. Clin Neuropsychol 2:133-148.

Charness ME, DeLaPaz RL (1987) Mammillary body atrophy in Wernicke's encephalopathy: antemorten identification using magnetic resonance imaging. Ann Neurol 22:595-600.

Damasio AR (1984) The anatomic basis of memory disorders. Semin Neurol 4:223-225.

Damasio AR, Eslinger P, Damasio H, Van Hoesen GW, Cornell S (1985) Multimodal amnestic syndrome following bilateral temporal and basal forebrain damage: the case of patient D.R.B. Arch Neurol 42:252-259.

Gerard G, Weisberg L (1986) MRI periventricular lesions in adults. Neurology 36:998-1001.

Graff-Radford N, Damasio H, Yamada T, Eslinger PJ, Damasio AR (1985) Nonhaemorrhagic thalamic infarction. Brain 108:485--516.

Janowsky JS, Shimamura AP, Kritchevsky M, Squire LR (1989) Cognitive impairment following frontal lobe damage and its relevance to human amnesia. Behav Neurosci 103:548-560.

Jernigan TL, Schaffer K, Butters N, Cermak LS (1989) Brain morphology on MR images in Korsakoff's syndrome. Soc Neurosci Abst 15:4.

Kaplan EF, Goodglass H, Weintraub S (1983) The Boston naming test. Philadelphia: Lea and Febiger.

Mahut H, Moss M (1984) Consolidation of memory: the hippocampus revisited. In: Neuropspychology of memory (Squire LR, Butters N, eds), pp 297-315. New York: Guilford.

Mair WGP, Warrington EK, Weiskrantz L (1979) Memory disorder in Korsakoff psychosis: a neuropathological and neuropsychological investigation of two cases. Brain 102:749-783.

Markowitsch HJ (1988) Diencephalic amnesia: a reorientation towards tracts? Brain Res Rev 13:351-370.

Mattis S (1976) Dementia rating scale. In: Geriatric psychiatry, Vol. 1 (Bellack R, Karasu B, eds), pp 77-121. New York: Grune and Stratton.

Mayes AR, Meudell PR, Mann D, Pickering A (1988) Location of lesions in Korsakoff's syndrome: neuropsychological and neuropathological data on two patients. Cortex 24:367-388.

Milner B (1972) Disorders of learning and memory after temporal lobe lesions in man. Clin Neurosurg 19:421-446.

Mishkin M, Spicgler BJ, Saunders RC, Malamut BJ (1982) An animal model of global amnesia. In: Toward a treatment of Alzheimer's disease (Corkin S, Davis KL, Growdon JH, Usdin EJ, Wurtrman RJ, eds), pp 235-247. New York: Raven.

Mori E, Yamadori A, Mitani Y (1986) Left thalamic infarction and disturbance of verbal memory: a clinicoanatomical study with a new method of computed tomographic stereotaxic lesion localization. Ann Neurol 20:671-676.

Osterrieth PA (1944) Le test de copie d'une figure complexe [The test of copying a complex figure]. Arch Psychol 30:306-356.
Parkin AJ (1984) Amnesic syndrome: a lesion-specific disorder? Cortex 20:479-508.

Press GA, Amaral DG, Squirc LR (1989) Hippocampal abnormalities in amnesic patients revealed by high-resolution magnetic resonance imaging. Nature 341:54-57.

Rapaport D (1942) Emotions and memory. Baltimore: Williams and Wilkins.

Rey A (1964) L'examen clinique en psychologie [The clinical exam in psychology]. Paris: Universitaires de France.

Schacter DL (1985) Multiple forms of memory in humans and animals. In: memory systems of the brain: animal and human cognitive processes (Weinberger N, Lynch G, McGaugh J, eds), pp 351-379. New York: Guilford.

Shimamura AP, Jernigan TL, Squire LR (1988) Korsakoff's syndrome: radiological (CT) findings and neuropsychological correlates. J Neurosci 8:4400-4410.

Squire LR (1986) Mechanisms of memory. Science 232:1612-1619.

Squire LR (1987) Memory and brain. New York: Oxford UP.

Squire LR, Frambach M (1990) Cognitive skill learning in amnesia. Psychobiology 18:109-117.

Squire LR, Moore RY (1979) Dorsal thalamic lesion in a noted case of human memory dysfunction. Ann Neurol 6:503-506.

Squire LR, Zola-Morgan S (1983) The neurology of memory: the case for correspondence between the findings for human and nonhuman primate. In: The physiological basis of memory, $2 \mathrm{~d}$ ed (Deutsch JA, ed), pp 199-268. New York: Academic.

Squire, LR, Amaral DG, Zola-Morgan S, Kritchevsky M, Press G (1989a) Description of brain injury in the amnesic patient N.A. based on magnetic resonance imaging. Exp Neurol 105:23-25.

Squire LR, Haist F, Shimamura AP (1989b) The neurology of memory: quantitative assessment of retrograde amnesia in two groups of amnesic patients. J Neurosci 9:828-839.

Talland GA (1965) Deranged memory. New York: Academic.

Victor M, Adams RD, Collins GH (1989) The Wernicke-Korsakoff syndrome and related neurological disorders due to alcoholism and malnutrition, 2d ed. Philadelphia: F. A. Davis.

von Cramon DY, Hebel N, Schuri U (1985) A contribution to the anatomical basis of thalamic amnesia. Brain 108:993-1008.

Warrington EK (1984) Recognition memory test. Windsor: NFERNelson.

Wechsler D (1987) Wechsler memory scale-revised. San Antonio: Harcourt Brace Jovanovich.

Weiskrantz L (1987) Neuroanatomy of memory and amnesia: a case for multiple memory systems. Human Neurobiol 6:93-105.

Winocur G, Oxbury S, Agnetti V, Davis C (1984) Amnesia in a patient with bilateral lesions to the thalamus. Neuropsychologia 22:123-144.

Zola-Morgan S, Squire LR (1990) Identification of the memory system damaged in medial temporal lobe amnesia. In: The biology of memory (Squire LR, Lindenlaub E, eds). Stuttgart: F. K. Schattauer.

Zola-Morgan S, Squire LR, Amaral DG (1986) Human amnesia and the medial temporal region: enduring memory impairment following a bilateral lesion limited to field CA1 of the hippocampus. J Neurosci 6:2950-2967.

Zola-Morgan S, Squire LR, Amaral DG (1989) Lesions of the hippocampal formation but not lesions of the fornix or the mammillary nuclei produce long-lasting memory impairment in monkeys. J Neurosci 9:898-913.

Zola-Morgan S, Squire LR, Amaral DG (1990) The components of the medial temporal lobe memory system. In: Learning and memory, discussions in neurosciences (Squire LR, Mishkin M, Shimamura A, eds). Amsterdam: Elsevier. 